\title{
IX. On radiation from a cylindrical wall
}

\section{A.C. Bartlett B.A.}

To cite this article: A.C. Bartlett B.A. (1920) IX. On radiation from a cylindrical wall, Philosophical Magazine Series 6, 40:235, 111-113, DOI: 10.1080/14786440708636101

To link to this article: http://dx.doi.org/10.1080/14786440708636101

册 Published online: 08 Apr 2009.

Submit your article to this journal $\pi$

Џlll Article views: 3

Q View related articles ¿

Citing articles: 8 View citing articles $\sqsubset$ 


\section{[ 111 ]}

IX. On Radiation from a Cylindrical Wall.
By A. C. BaRTLETT, B.A.*

$\mathrm{O}^{\mathrm{N}}$ page 359 and succeding pages of the Phil. Mag. of March 1920, in a paper under the above heading, an expression is obtained for the amount of heat radiated from the inner walls of a vertical cylinder on to a horizontal coaxial disk.

The result is obtained from first principles by quadruple integration over the surfaces of the disk and cylinder, and the process is long and laborions. It is, however, possible to deduce the result, by a method which is not only much simpler but much more powerful.

It has been shown by Sumpmer (Phys. Soc. 1892) that if in element $a \mathrm{~S}$ of the surface of a sphere is radiating according to a cosine law, and $d s$ is any other element of surface of the sphere, then the radiated energy received by $d s$ from $d \mathbb{S}$ is independent of the position of $d s$ on the sphere. $d s$ is

It can be shown that the amount of energy received by

$$
\frac{\pi \mathrm{N} a \mathrm{~S} d s\left(\mathrm{~T}_{\mathrm{1}}^{4}-\mathrm{T}_{2}^{4}\right)}{\mathrm{A}}
$$

where $\mathrm{N}$ is the normal radiation from $d \mathrm{~S}$; ' $\mathrm{I}_{1}$ is the temperature of $d \mathrm{~S}$ and $\mathrm{T}_{2}$ of $d s ; \mathrm{A}$ is the area of the sphere.

This result will obviously hold for finite portions of the spherical surface; therefore, if $\mathrm{S}$ and $s$ are two non-intersecting curves lying on a sphere enclosing spherical areas $\mathrm{S}^{\prime}$ and $s^{\prime}$ respectively, and maintained at constant temperatures $\mathrm{T}_{1}$ and $\mathrm{T}_{2}$ respectively, the energy received by $s^{\prime}$ from $\mathrm{S}^{\prime}$ is

$$
\frac{\pi \mathrm{NS}^{\prime} s^{\prime}}{\mathrm{A}}\left(\mathrm{T}_{1}{ }^{4}-\mathrm{T}_{2}{ }^{4}\right)
$$

This result will still be true if the surfaces $s^{\prime}$ and $S^{\prime}$ are replaced by any two surfaces $s^{\prime \prime}$ and $S^{\prime \prime}$ provided that $s^{\prime \prime}$ and $S^{\prime \prime}$ satisfy the following three conditions:-

(1) 'Their boundary curves $s$ and S lie on a sphere.

(2) If $\mathrm{V}$ is any point in $\mathrm{S}^{\prime \prime}$, then no portion of the surface $s^{\prime \prime}$ visible from $V$ lies outside the cone vertex $V$ passing through the curve $s$.

(3) If condition (2) is true when $S$ and $s$ and $S^{\prime \prime}$ and $s^{\prime \prime}$ are interchanged.

* Communicated by the Author. 
Provided these conditions are satisfied, the energy received by $s^{\prime \prime}$ from $\mathrm{S}^{\prime \prime}$ will be

$$
\pi \mathrm{NS}^{\prime} s^{\prime}\left(\mathrm{T}_{1}{ }^{4}-\mathrm{T}_{2}{ }^{4}\right)
$$

From this result the problem can be readily solved. With the same figure as on page 360 and using the same notation, consider any point $\mathrm{V}$ on the disk. It is receiving radiation from a surface of temperature $T_{1}$ occupying the solid angle between the two cones having $V$ as vertex and the circles $M$ and $\mathrm{K}$ as bases. The disk therefore is receiving from the inner walls an amount of energy equal to that which it would receive from a circular disk $\mathbf{K}$, less what it would receive from a circular disk $M$, both disks having the same temperature and emissivity as the walls of the cylinder.

Construct a sphere of which the circle $K$ and the receiving disk $\mathrm{O}$ are small circles. The radius of this sphere is

$$
\sqrt{b^{2}+\frac{\left(a^{2}-b^{2}-x_{1}^{2}\right)^{2}}{4 x_{1}^{2}}}
$$

By substitution of the spherical areas of the two disks in the formula, the result obtained after reduction is that the energy received by the disk $\mathrm{O}$ from a disk $\mathrm{K}$ is:

$$
\frac{\pi \sigma}{2}\left[\sqrt{\left(x_{1}^{2}+a^{2}+b^{2}\right)^{2}-4 a^{2} b^{2}}-\left(x_{1}^{2}+a^{2}+b^{2}\right)\right] \times\left(\mathrm{T}_{1}^{4}-\mathrm{T}_{2}{ }^{4}\right) \text {. }
$$

Similarly, the energy received by the disk $O$ from a disk at $M$ would be

$$
\frac{\pi \sigma}{2}\left[\sqrt{\left(x_{2}^{2}+a^{2}+b^{2}\right)^{2}-4 a^{2} b^{2}}-\left(x_{2}{ }^{2}+a^{2}+b^{2}\right)\right]\left(\mathrm{T}_{1}{ }^{4}-\mathrm{T}_{2}{ }^{4}\right) .
$$

Therefore the energy receired by the disk $O$ from the walls of the cylinder is

$$
\begin{aligned}
\frac{\pi \sigma}{2}\left(\mathrm{~T}_{1}^{4}\right. & \left.-\mathrm{T}_{2}^{4}\right)\left[\sqrt{\left(x_{1}^{2}+a^{2}+b^{2}\right)^{2}-4 a^{2} b^{2}}\right. \\
& \left.-\sqrt{\left(x_{2}^{2}+a^{2}+b^{2}\right)^{2}-4 a^{2} b^{2}}-x_{1}^{2}+x_{2}{ }^{2}\right] .
\end{aligned}
$$

This is the result obtained on page 364 .

In the same manuer an expression can be obtained for the energy received by a circular disk from a surface bounded by any number of circles, provided that each of these circles is co-spherical with the disk and conditions (2) and (3) stated previously are satisfied.

This result can be generalized for the case where the radiating 
Lippich's Projective Theorem in Geometrical Optics. 113 surface is bounded by any curves and the receiving surface is bounded by a circle provided the same conditions are satisfied.

Any further attempt to generalize by allowing the bounding curves of the receiving surface to be non-planar reduces at once to the original theorem, since a non-planar curve cannot lie on more than one sphere.

Research Laboratories of the General Electric Co., Ltd., London.

$\mathrm{X}$. On a Projective Theorem of Lippich's in Geometrical Optics. (With a Note on the Equations of the Projection of a Siraight Line on a Plane.) By Alice EvererT *.

THE theorem referred to is the following:-If the corresponding incident and refracted portions of a ray, which is infinitely near to a chief ray lying in a principal section of a refracting surface, be projected upon either the tangential or sagittal sections of the chief ray, then the projections also correspond.

By near rays are meant rays which are nearly parallel and are ineident at near points where the normals are nearly, parallel.

The tangential section is defined as that principal section of the surface, at the point of incidence of the chief ray, which contains the chief ray and normal; it coincides with the plane of incidence. The sagittal plane is defined as a plane through the chief ray perpendicular to the plane of incidence. The sagittal sections for the incident and refracted chief rays are in general different, and not principal sections.

The theorem was proved by Lippich (1877) for the sphere only, in an essay on Refraction and Reflexion of Infinitely Thin Ray Systems by Spherical Surfaces (Vienna Academy, Denkschriften, Band 38, p. 176 (1878)). Culmann extends it to non-spherical surfaces in his chapter in von Rohr's 'Theorie der uptischen Instrumente,' Band 1, pp. 183-185.

Its interest lies in the fact that it enables the path, after refraction at a non-spherical surface, of any oblique ray infinitely near to a ray in a piincipal section to be found by applying to its projections the ordinary method adopted for rays in an axial plane of a spherical refiacting surface. We

* Communicated by the Author.

Phil. Mag. S. 6. Vol. 40. No. 235. July 1920. 